\title{
Chemical aspects of viscous flow in planetary mantles
}

\author{
Robert F. Mueller \\ Geophysics Branch, NASA/Goddard Space Flight Center, \\ Greenbelt, Maryland, 20771 U.S.A.
}

(Received September 29, 1975)

\begin{abstract}
A critique is presented of the various mathematical rheological models, and their applications to the mantles of the Earth and the terrestrial planets is discussed. One of the models considered is derived from absolute reaction rate theory of chemical kinetics and allows for automatic transition between Newtonian (strain rate proportional to stress) and non-Newtonian viscous flow depending on the differential stress and the strain rate. A good fit to data is obtained when this model is applied to the post glacial Fennoscandian uplift. The deduced strain rate, as obtained from the assumption of proportionality between strain rate and rate of uplift, is in the range of $10^{-16}$ to $10^{-15} \mathrm{sec}^{-1}$, while the deduced viscosities fall in the range of $10^{22}$ and $10^{23}$ poises with uncertainties of an order of magnitude. Flow is found to be non-Newtonian but is becoming increasingly Newtonian with time.

The various thermodynamic parameters of viscous flow, including pressure and temperature sensitivity, are also discussed and the viscous relaxation times of the different terrestrial planets are compared in terms of their temperatures. From this analysis it is concluded that the relatively low relief and the recently discovered circular depressions on Venus are probably a result of high lithospheric temperatures on this planet. The depressions are probably due to subsidence around basic volcanic centers and correspond to shield volcanos on Earth and Mars. Application of the same theory to terrestrial global plate tectonics leads to the conclusion that there should be viscous accretion of mantle material on the postulated cool descending slab of oceanic crust and that the viscosity of planetary mantles should be increasing with time.
\end{abstract}

\section{INTRODUCTION}

It has long been recognized that a major type of deformation that occurs both within the Earth's crust and mantle is that which depends on flow of solid rocks and which is very similar to flow in fluids. It is also quite generally accepted now that such flow is an activated process in which individual particles (atoms, ions, vacancies, etc.) are involved and as such falls within the realm of chemical kinetics.

In the Earth's crust flow is manifested as folded and recrystallized metasedimentary beds, deformed relicts such as fossils and as larger structures such as gneiss domes and certain batholiths. Mantle flow by contrast is evident largely as secondary phenomena such as in vertical movements associated with post glacial uplift. Although deformed inclusion of volcanic rocks and kimberlites have been interpreted as indicating mantle flow it is not possible to relate these to a particular type of deformation. By extension of the post glacial uplift phenomena, however, it may be inferred that viscous mantle flow should also play an important role in proposed models of global "plate" tectonics which involve large scale horizontal and vertical movements of both crust and mantle. In a further extension to the inner or terrestrial planets, whose gross compositions are not far different from that of Earth, it is also clear that viscous behavior is fundamental to an understanding of their surface features. 
The common agreement as to the kinetic nature of viscous flow of rocks does not however, extend to the precise mechanisms involved nor to the analytic representation of these mechanisms. Generally, however, students of the subject have come to favor such mechanisms as internal grain deformation and grain boundary sliding due to the flow of vacancies and a counter current of particles such as $0^{2-}$ ions or 2) vacancy and particle flow associated with the movement of dislocations either in glide planes or as dislocation climb out of glide phases. The favoring of these mechanisms appears to be a consequence largely of roles they have played in experimental deformation of metals and ceramics. However, the visual aspect of most deformed crustal rocks which appear to have behaved in a viscous manner is one of profound recrystallization. This does not mean that dislocations were not present during deformation but it does cast doubt on whether their movement was rate determining. It is possible that other yet poorly understood kinetic mechanisms are important in recrystallization flow.

Some of the most frequently discussed mathematical models for flow in planetary mantles are those of Nabarro (1948), Herring (1950) and Cobel (1963). These models have had some success in describing flow in fine grained ceramic materials. The NabarroHerring model evaluates the diffusion, through the crystal interior, of vacancies and a counter current of ions. Ion diffusion occurs from crystalline boundaries of high stress to boundaries of low stress. The resulting expression for the strain rate $\dot{\gamma}$ is

$$
\dot{\gamma}=\alpha \tau D_{1} \Omega / R^{2} \mathrm{k} T
$$

with the following definitions:

$\alpha=$ a constant depending on the nature of the material

$\tau=$ the differential stress

$D_{1}=$ the lattice diffusion coefficient

$\Omega=$ vacancy volume

$R=$ grain size

$\mathrm{k}=$ Boltzmann's constant

$T=$ the absolute temperature

$D_{1}$ and $\Omega$ are taken to represent the $0^{2-}$ ion since this usually is the slowest diffusing species according to experimental evidence, and is thus rate determining. Special characteristics of (1) are its content of explicit parameters, the inverse dependence on the square of the grain size and the direct proportionality between stress and strain rate when all other parameters are held constant.

An analogous expression derived by COBEL (1963) for vacancy diffusion along crystalline boundaries is the following:

$$
\dot{\gamma}=\mathrm{C}_{\tau} D_{\mathrm{b}} W \Omega / R^{3} \mathrm{k} T
$$

in which $\mathrm{C}$ is a constant of the order of $150, D_{\mathrm{b}}$ is the coefficient of boundary diffusion and $W$ is the boundary width. Diffusion may in this case be controlled by cations such as $\mathrm{Al}^{3+}$ since the diffusion of $0^{2-}$ is greatly enchanced in crystal boundaries. The salient characteristics of (2) are the dependence of $\dot{\gamma}$ on the inverse third power of $R$ the grain diameter and, as in (1), a direct proportionality to $\tau$. Then both (1) and (2) can result in linear or Newtonian type flow.

A great variety of models have been proposed for the different forms of dislocation activated flow. WEERTMAN $(1968,1970)$ in particular has derived a number of such models and has applied them to flow in the Earth's mantle. Although it is not possible to review all these models here I present the following expressions for dislocation glide and dislocation climb:

$$
\text { glide: } \quad \dot{\gamma}=\alpha^{\prime} D(\tau / \mu)^{2}(\tau \Omega / \mathrm{k} T)=\mathrm{B} \tau^{3}
$$




$$
\text { climb: } \quad \dot{\gamma}=\alpha^{\prime \prime} D(\tau / \mu)^{\mathrm{m}}(\tau \Omega / \mathrm{k} T)=\mathrm{B}^{\prime} \tau^{\mathrm{n}}
$$

In these expressions $\alpha^{\prime}$ and $\alpha^{\prime \prime}$ are constants characteristic of the material and $D$ is the coefficient of diffusion. This expression is also explicit since it contains $\mu$ the shear modulus, which is an elastic property of the material. In each case the equation results in a power law form in which all the parameters are regarded as essentially constant at constant pressure, temperature and composition and are lumped together to form the constant factors $B$ and $B^{\prime}$. Despite the explicit derivation of (4) the presence of $n$ in particular results in this equation being essentially of empirical curve fitting utility. Although $\mathrm{n}$ may be successfully fitted to a variety of experimental data on ceramics and metals it is found to vary widely between one and 8 . In a number of cases favorable correlation of diverse materials is obtained by plotting $\dot{\gamma} / D$ against $\tau / \mu$ when $D$ is the diffusion coefficient of the slowest moving species (KIRBY and RALEIGH, 1973).

One characteristic of all the equations presented thus far is that the power $n$ is regarded as fixed throughout the range of stresses to which it is thought to be applicable. In this regard the Nabarro-Herring and Coble expressions may be regarded as having $\mathrm{n}=1$. Thus there is no allowance for a smooth transition from Newtonian to non-Newtonian flow, and $\mathrm{n}$ must be changed discontinuously and arbitrarily to fit the data. One result of this rigidity is a tendency for the investigator to classify a particular type of flow as non-Newtonian where $\mathrm{n}$ is found to deviate from unity, thus disregarding the possibility that such flow might become Newtonian at low strain rates and stresses. While $\mathrm{n}$ has been found to be larger than one for many types of flow under experimental conditions on coarse grained materials, these experiments have generally been carried out under stresses and strain rates orders of magnitude greater than those which prevail in planetary mantle flow.

A theory which takes a different tack than the foregoing and which has proved to be of great general applicability in chemical kinetics is the theory of absolute reaction rates (Glasstone et al., 1941). According to this theory we may write

$$
\dot{\gamma}=\frac{2 \lambda \mathrm{K}}{\lambda_{1}} \sinh \frac{V \tau}{2 \mathrm{k} T},
$$

where $\lambda$ and $\lambda_{1}$ are the atomic-scale distances between two atomic equilibrium positions and the separation of the shearing layers respectively. $K$ is the specific rate constant and $V$ is the "characteristic shear volume" (REE and EYRING, 1955) and is equal to the product $\lambda \lambda_{2} \lambda_{3}$, where $\lambda_{2}$ and $\lambda_{3}$ are the dimensions of this unit of flow perpendicular and parallel respectively to the direction of shear in the plane of shear.

Whether (5) is preferred over the previously discussed expressions for $\dot{\gamma}$ may in part be a matter of taste. In some cases also the power law formula appears to provide a superior fit to experimental data (HEARD and RALEIGH, 1972), although this conclusion is far from settled, since (5) lends itself well to combination in a series of terms. Such terms may represent simultaneously acting mechanisms of almost equal importance in certain stress ranges. The attraction of (5) and its underlying derivation is the combination of generality with simplicity. Deformation and diffusion in this model are treated in the same way as all other chemical reactions are treated. Thus $\lambda$ is always the distance between potential energy wells or the "jump distance" which corresponds to the reaction coordinate in other chemical reactions. In this general form there is no explicit statement regarding such mechanisms as involve vacancy diffusion or dislocations but only the general movement of particles across energy barriers in shearing motion.

An important aspect of all the equations presented is the dependence of the strain rates on the temperature and confining pressure as distinguished from the differential stress. These effects appear as systematic changes in $D, \mathrm{~B}$, and $\mathrm{K}$ in particular. To see this effect we can write the expression for the strain as 


$$
\dot{\gamma}=\operatorname{Af}(\tau) \exp \left(E^{*} / \mathrm{R} T-P \Delta V^{*} / \mathrm{R} T\right) .
$$

in which $\mathrm{A}$ is a constant $\mathrm{f}(\tau)$ is a function of $\tau$ (as $\tau^{\mathrm{n}}$ for example), $\mathrm{R}$ is the gas constant and $E^{*}$ is experimental energy of activation. The term $P \Delta V^{*}$ is the energy contribution of the confining pressure $P$, while $\Delta V^{*}$ is the volume change of activation. Expression (6) is equivalent to the familiar Arrhenius equation.

An alternative to (6) is an expression of the rate constant $\mathrm{K}$ in (5) in terms of the entropy and enthalpy changes of activation $\Delta S^{*}$ and $\Delta H^{*}$ as well as $\Delta V^{*}$ :

$$
\mathrm{K}=\frac{\mathrm{k} T}{\mathrm{~h}} \exp \left(-\Delta H^{*} / \mathrm{R} T+\Delta S^{*} / \mathrm{R}-P \Delta V^{*} / \mathrm{R} T\right) \text {. }
$$

Here $\mathrm{h}$ is Planck's constant. We may also write

$$
-\Delta H^{*}-P \Delta V^{*}+\Delta S^{*} T=\Delta G^{*}
$$

when $\Delta G^{*}$ is the Gibbs free energy change of activation.

Unfortunately $\Delta V^{*}$ the volume change of activation is not at all known for mantle materials such as dunites or peridotites so that it has become the practice to estimate the effect of pressure by use of the following empirical correlation (SHERBY and SiMMAD, 1961; SHEWMAN, 1963; WEERTMAN, 1970):

$$
-\frac{E^{*}}{\mathrm{R} T}-\frac{P \Delta V^{*}}{\mathrm{R} T}=\mathrm{g} \frac{T_{\mathrm{m}}}{T}
$$

where $\mathrm{g}$ is a constant, $T_{\mathrm{m}}$ is the melting temperature at a pressure $P$ and $T$ is the ambient temperature. Also it is assumed that

$$
T_{\mathrm{m}}=T_{\mathrm{mo}}+\frac{\partial T_{\mathrm{mp}}}{\partial P}
$$

$T_{\text {mo }}$ being the melting temperature at zero pressure. Consequently,

$$
\mathrm{g}=\frac{E^{*}}{\mathrm{R} T_{\mathrm{mo}}}=\frac{\Delta V^{*}}{\mathrm{R}} \frac{\mathrm{d} T_{\mathrm{m}}}{\mathrm{d} p} .
$$

Although the foregoing equations have been applied with success to a wide variety of metals, ceramics and salts, experimental data on materials inferred to comprise the Earth's mantle are more limited. However, particularly important experiments have been described by Raleigh (1968), Carter and Ave'Lallemant (1970), Ave'Lallemant and CARTEr (1970), Kirby and Raleigh (1973) and Post and Griggs (1973). These experiments have all been performed on rocks consisting chiefly of olivine with some pyroxene (dunite, lherzolite, peridotite, etc.), which are inferred to be most representative of the mantle above $400 \mathrm{~km}$ depth. These experiments have shown that olivine deforms by plastic flow on various slip planes, by polygonization due to dislocation climb and through pervasive recrystallization. Plastic phenomena, involving slip on planes of various orientations is characteristic of experimental temperatures below $1,000^{\circ} \mathrm{C}$ and high strain rates. Different slip planes come into play with increasing temperature and decreasing strain rates. At temperatures above $1,000^{\circ} \mathrm{C}$ dislocation climb leading to the formation of polygonal subgrains and recrystallization begin to dominate. Deformation, and in particular recrystallization, is facilitated by the presence of water. Experimental activation energies are of the order of 100 kilocalories per mole but the presence of water lowers them 
significantly. Such high values of $E^{*}$ indicates that the viscosity is highly temperature dependent.

It is highly significant that the experiments were all confined to stresses in the kilobar range and with strain rates above $10^{-8} \mathrm{sec}^{-1}$. Confining pressures range up to 30 kilobars. By contrast differential stresses for the important mantle processes are inferred to fall in the range of several hundred bars or less while strain rates should be less than $10^{-14} \mathrm{sec}^{-1}$. Also pressures may exceed 30 kilobars by several factors. These facts point up the need to correlate these experimental data with firm data of good precision on actual flow phenomena within the mantle. The analysis of post glacial isostatic uplift in Fennoscandia appears to be quite useful in this regard.

\section{Rheological Properties of Earth's Upper Mantle from Post Glacial Uplift}

The importance of post glacial uplift to the understanding of mantle properties was given great impetus from the pioneering work of HASKELL (1937) which indicated a viscosity of the order of $10^{22}$ poises. Subsequently important contributions to mantle fluid dynamics was made by VenNing-Meinesz (1937), NisKanen (1948), Von Bemmelen and Berlage (1954) TaKeuchi and Hasegawa (1965), AityushKov (1967), McKenzie (1967), MCConnell (1968) and LliboutRy (1971) among others.

More recently Post and GRIGGs (1973) made a valuable contribution to these studies by suggesting how the remaining uplift $\zeta$ and the time rate of uplift $\mathrm{d} \zeta / \mathrm{dt}=\dot{\zeta}$ in Fennoscandia may be related to the average effective strain rate $\dot{\gamma}$ and shearing stress $\tau$ which enter into the rate equation for the flow process. According to them we may write:

$$
\dot{\gamma}=\mathrm{K}_{1} \dot{\zeta}
$$

and

$$
\tau=\mathrm{K}_{2} \zeta
$$

in which $\mathrm{K}_{1}$ and $\mathrm{K}_{2}$ are constants. No values or explicit expressions for these constants were given by Post and GRIGGs. However, these authors were able to show that by use of these relations the geological uplift data of SAURAmo (1958) as interpreted and supplemented by McConNell (1968) could be closely fitted by an integral form of equation (4) namely

$$
\zeta^{1-\mathrm{n}}=\zeta_{\max }^{1-\mathrm{n}}+\mathrm{C}(1-\mathrm{n}) \mathrm{t} .
$$

In this equation $\zeta_{\max }$ is the maximum central depression at the time of glacial retreat and $\mathrm{C}$ and $\mathrm{n}$ are constants.

One of the major conclusions of PosT and GRIGGS and which had been arrived at earlier by LLIBOUTRY (1971) was that mantle materials are non-Newtonian in behavior with $\mathrm{n}$ in equation (13) assuming a value near 3. The value obtained by PosT and GRIGGS from a synthesis of the SAURAMO-MCConNell data is $n=3.2 \pm 0.3$ under the assumption that the presently remaining central uplift is 180 meters. Furthermore the curve of $\zeta v$. time obtained by them is remarkably close to the curve presented earlier by LLIBOUTRY (1971) who utilized the data of LIDÉN (1938) from the beaches at the mouth of the Angerma River in the central region of uplift. In fact the two curves (Figs. 1 and 2) practically coincide over much of the range although LLIBOUTRY's data are based on the assumption that the present uplift remaining is 170 meters. However, none of the cited authors attempted to evaluate the uncertainties in these data numerically. WALCOTT (1973) has however, given rough values for these uncertainties for the similar Laurentide uplift in Canada. 


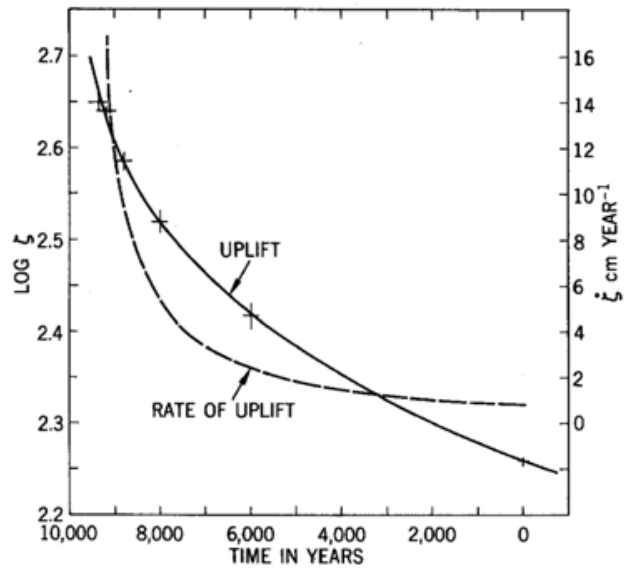

Fig. 1.

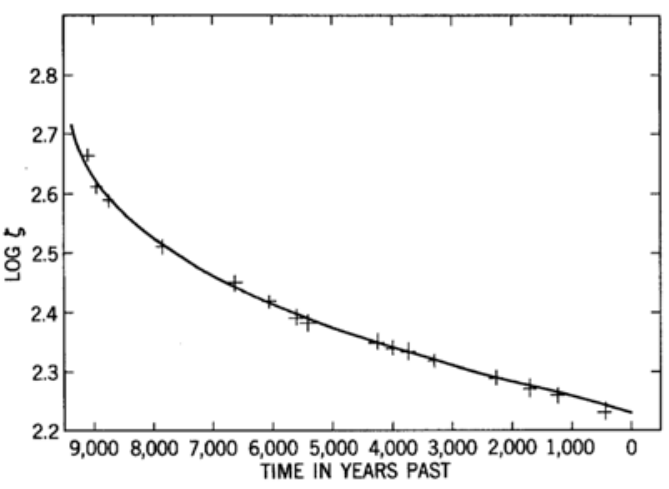

Fig. 2.

Fig. 1. Uplift and rate of uplift for the Fennoscandian post-glacial uplift as a function of time. $\zeta$ is the central uplift remaining at various times in the past. Data points are as presented by POST and GRIGGS (1973) following MCCONNELL (1968) and are based on original data of SAURAMO (1958). Presently remaining uplift in the central region is assumed to be 180 meters. Sizes of the crosses reflect estimated minimum uncertainties. The curve is based on reaction rate theory.

Fig. 2. Uplift for the Fennoscandian post-glacial uplift as a function of time. $\zeta$ is the central uplift remaining at various times in the past. Data points are as presented by LLIBOUTRY (1971) and are based on the original data of LIDÉN (1938). Presently remaining uplift is assumed to be 170 meters. The curve is based on reaction rate theory.

As a consequence of the few data points utilized by Post and Griggs (1973) the excellence of their fit of equation (13) to these data must be regarded as partly fortuitous as was recognized by them. We have also seen that despite the theoretical basis for equation (13) its use here is essentially empirical and it does not automatically reduce to the linear form at low strain rates as is required by Newtonian behavior. This is of course a consequence of the fixed value of $\mathrm{n}$ which is regarded as independent of stress.

If on the other hand, we substitute relations (11) and (12) into (5) we obtain:

$$
\dot{\zeta}=\mathrm{C}_{0}^{\prime} \sinh \mathrm{A}^{\prime} \zeta,
$$

where

$$
\mathrm{C}_{0}^{\prime}=\frac{2 \lambda \mathrm{K}}{\lambda_{1} \mathrm{~K}_{1}} \quad \mathrm{~A}^{\prime}=\frac{V \mathrm{~K}_{2}}{2 \mathrm{k} T}
$$

Integration of (14) then gives

$$
\log \tanh \mathrm{A} \zeta+\mathrm{C}=\mathrm{C}_{0} \mathrm{t} .
$$

Here $\mathrm{C}$ is a constant of integration which is determined by the presently remaining uplift in the central region of uplift. Also

$$
\mathrm{C}_{0}=\frac{\mathrm{A}^{\prime} \mathrm{C}_{0}^{\prime}}{2.303}, \quad \mathrm{~A}=\frac{\mathrm{A}^{\prime}}{2}
$$

Figure 1 and Table 1 show a least squares fit of equation (16) to the same data 
Table 1. Uplift remaining and rate of uplift as a function of time calculated according to absolute reaction rate theory. The data are plotted in Fig. 1.

\begin{tabular}{cccc}
\hline $\begin{array}{c}t \\
\text { (time past in years) }\end{array}$ & $\begin{array}{c}\zeta \\
\text { (uplift remaining in meters) }\end{array}$ & $\log \zeta$ & $\begin{array}{c}\dot{\zeta} \\
\text { (in } \mathrm{cm}^{-1} \text { ) }\end{array}$ \\
\hline 0.0 & 180 & 2.226 & 0.872 \\
2040 & 200 & 2.230 & 1.109 \\
3650 & 220 & 2.234 & 1.408 \\
4920 & 240 & 2.238 & 1.78 \\
5920 & 260 & 2.241 & 2.25 \\
6710 & 280 & 2.245 & 2.86 \\
7330 & 300 & 2.248 & 3.62 \\
7820 & 320 & 2.251 & 4.58 \\
8210 & 340 & 2.253 & 5.79 \\
8520 & 360 & 2.256 & 7.32 \\
8770 & 380 & 2.258 & 9.26 \\
8960 & 400 & 2.260 & 11.71 \\
9110 & 420 & 2.262 & 14.82 \\
9230 & 440 & 2.264 & 18.74 \\
9330 & 460 & 2.266 & 23.7 \\
\hline
\end{tabular}

utilized by Post and Griggs (1973). The resulting values of the constants, under the assumption used by PosT and GRIGGs that the central uplift remaining is 180 meters, are $\mathrm{A}=5.87 \times 10^{-3} \mathrm{~m}^{-1}$ and $\mathrm{C}_{0}=1.09 \times 10^{-5} \mathrm{yr}^{-1}$. The constant $\mathrm{A}$ changes very little if alternative values of 150 and 210 meters are assumed for the remaining uplift, as was also done by Post and GRIGGs, but $\mathrm{C}_{0}$ assumes values of $1.57 \times 10^{-5}$ and $7.5 \times 10^{-6} \mathrm{yr}^{-1} \mathrm{res}^{-}$ pectively under these assumptions. A fit of equation (16) to LLIBOUTRY's data is shown in Fig. 2 and this yields $\mathrm{A}=5.45 \times 10^{-3} \mathrm{~m}^{-1}$ and $\mathrm{C}_{0}=1.43 \times 10^{-5} \mathrm{yr}^{-1}$ for a remaining central uplift of 170 meters. This curve has residuals which are generally less than 100 years for 17 data points.

As explained by MCCONNELL and by the other authors cited, the errors and uncertainties in the uplift values are difficult to determine. An examination and comparison of the data of MCCONNELL and LLIBOUTRY indicates that the uncertainty is probably at least 10 meters in $\zeta$ and 200 years in t. Consequently these values have been incorporated as error crosses in Fig. 1 as an illustration. The size of the crosses in Fig. 2 have no significance however.

Since both equations (13) and (16) result in residuals of 50 years or less in $t$ as applied to the MCConNell-SaURAmo data as adapted by Post and GrigGS, there is little to choose between them in this regard. However, if we extend the two models into time future there is great divergence between them as may be seen from Fig. 3. For example at $10^{5}$ years equation (16) yields $\zeta=10$ meters with essentially Newtonian behavior, but according to (13) there are still more than 60 meters of uplift remaining and $n$, which

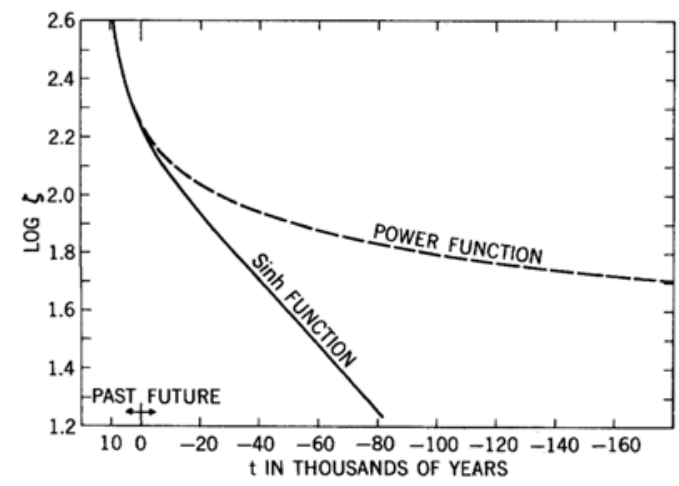

Fig. 3. Uplift of the Fennoscandian postglacial uplift as a function of time for two rheological models. The full curve is the same as that of Fig. 1 extended into time future. Dashed curve is based on power law of uplift as derived by POST and GRIGGS (1973). 
must equal unity for Newtonian flow still has the same value it had at the far higher stresses and strain rates at the beginning of uplift. More generally equation (16) approximates linear (Newtonian) behavior closely in the range $t>50,000$ years time future while equation (13) deviates widely from this model.

It is clear from the foregoing that there is nothing in existing data on post glacial uplift that would lead one to believe that the relation (13) represents a "general flow law" as stated by PoST and GRIGGs (1973). Rather this lack of uniqueness should be recognized as a common characteristic of curve fitting in certain ranges of variables, and should at the same time prevent us from taking any theoretical model too seriously.

The rate of uplift of the central area of uplift (Table 1, Fig. 1), which may be calculated directly from equation (14), is informative in that it indicates how rapidly Earth's crust was responding to mantle flow at the early period of glacial unloading. If the inferred mathematical relations are correct for this period the land should have risen at rates far exceeding ten centimeters per year which probably significantly exceeds the most rapid movement presently attributable to so-called plate tectonic movements. The rapidity of these movements seem to indicate that much of the crustal depression attributable to the thick ice load was removed during the comparatively short period of melting itself (LliboutRY, 1971) and that during this early period uplift may vertually have kept pace with melting.

In order to calculate the kinetic parameters $V$, and $\Delta G^{*}$ as well as the viscosity $\eta$ it is necessary to find explicit values of $\mathrm{K}_{1}$ and $\mathrm{K}_{2}$ and the effective temperature at which flow occurs must be known to calculate $V$ and $\Delta G^{*}$. The temperature may be estimated within 20 percent or so by reference to temperature depth curves if it is assumed that a single characteristic temperature of flow can be adopted and that the temperature-depth curves have the form ordinarily attributed to them. This is a consequence of the bending of such curves subparallel to the depth axis of the temperature-depth plot in the range of depth between 200 and 400 kilometers, where the flow is thought to be concentrated. If we adopt the temperature-depth curve of CLARK and RingwOOD (1964) for example, temperature in this depth range falls in the range of 1,200 to $1,800^{\circ} \mathrm{K}$. Consequently for purposes of illustration, I shall assume a temperature of $1,600^{\circ} \mathrm{K}$ in the calculations. As we shall see this assumption in no way influences the determination of the viscosity.

Although flow undoubtedly occurs over a range of depths and temperatures, the concept of a single effective or characteristic temperature is in harmony with the kinetic principle that movement of the lowest viscosity zone should dominate over competing zones of higher viscosity, if movement is most rapid in the former and if movement in such a zone does not critically depend on accompanying motion in high viscosity zones. This behavior conforms best to the notion of a relatively restricted flow channel as in certain proposed models (W ALCOTT, 1973). It should also be mentioned that if such channel flow is rate determining, it is implied that the crustal motion, which is the visible portion of the uplift and which must occur simultaneously with the mantle motion, occurs with greater ease than the latter although the crust has far greater viscosity. Such behavior probably results from the relative thinness of the crust.

A value of $\mathrm{K}_{1}$ may be obtained by estimating the radial distance $d$ which separates the central area of most rapid uplift from the region of zero uplift (Fig. 4). In this model shearing may be thought to be occurring on vertical planes perpendicular to $d$ resulting in movement with a velocity of uplift directly proportional to the distance from the point where $\dot{\zeta}=0$. In such proportional uplift $d$ is analogous to $\lambda_{1}$ on the atomic scale. Although there is some doubt as to the value of $d$, it appears to be of the order of 1,000 kilometers in McConnell's (1968) section of the uplift as based on Sauramo's (1958) data. Again the uncertainty appears to be about 20 percent.

The validity of the assumption of proportionality of uplift with distance from the region of zero uplift is also supported by MCConNELL's (1968) plot of the present rate of uplift as a function of distance from the uplift center. Thus the relation (11) becomes 


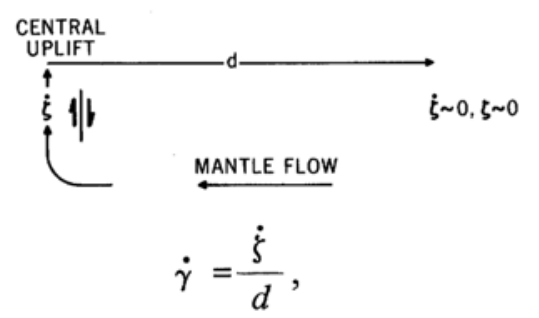

Fig. 4. Geometry used in deriving proportionality between strain rate and uplift. $\zeta$ is the uplift remaining while $d$ is the distance between the center of uplift and the point of zero uplift.

where $\mathrm{K}_{1}=10^{-8} \mathrm{~cm}^{-1}$.

Similarly $\mathrm{K}_{2}$ may be estimated by assuming that the effective shearing stress is determined by the depth of mantle material displaced by down-warping. Thus we set

$$
\tau=\delta_{\mathrm{m}} \mathrm{g} \zeta
$$

where $\delta_{\mathrm{m}}$ is the density of the mantle material, here taken as $3.3 \mathrm{gm} \mathrm{cm}^{-3}$ and $\mathrm{g}$ is the gravitational acceleration and which is assumed to have its surface value. Thus for relation (12) we have

$$
\mathrm{K}_{2}=\delta_{\mathrm{m}} \mathrm{g}=3234 \mathrm{gmcm}^{-2} \mathrm{sec}^{-2} .
$$

The proper value of $\tau$ to utilize here is somewhat debatable because of the resolution of stresses on the atomic scale but the value given above should be a maximum since it is proportional to the vertically directed bouyant force.

If it is assumed that (18) and (19) yield correct expressions for $K_{1}$ and $K_{2}$, equations (5), (14) and (17) may be combined to obtain $V$ :

$$
V=\frac{4 \mathrm{k} T \mathrm{~A}}{\delta \mathrm{mg}}
$$

At $T=1,600^{\circ} \mathrm{K}$ and with $\mathrm{A}=5.87 \times 10^{-5} \mathrm{~cm}^{-1}$

$$
\infty V=16,000 \times 10^{-24} \mathrm{~cm}^{3}
$$

or

$$
V^{1 / 3}=25.3 \AA,
$$

which is the mean dimension of the shear volume. Also from the foregoing we have:

$$
\frac{\lambda}{\lambda_{1}} \mathrm{~K}=\frac{2.303 \mathrm{C}_{0} \mathrm{~K}_{1}}{4 \mathrm{~A}}=3.4 \times 10^{-17} \mathrm{sec}^{-1} \text {. }
$$

If we assume that $\lambda=\lambda_{1}, \Delta G^{*}$ may be estimated from the definition:

$$
\Delta G^{*}=-2.303 \mathrm{R} T \log \frac{\mathrm{hK}}{2 \mathrm{k} T}
$$

In this expression $\mathrm{R}$ is the gas constant and $\mathrm{h}$ is Planck's constant. If $\mathrm{R}$ is taken in units of calories $\mathrm{deg}^{-1}, \Delta G^{*}=221,000 \mathrm{cal}$.

We note here that the shear volume $V$ is quite large, which seems to indicate that the effective distance $\lambda_{1}$ between shear layers is probably considerably larger than the jump distance $\lambda$. Thus the estimated value of $\Delta G^{*}$ is very uncertain. If however, $\lambda_{1}>\lambda$ as 
expected, $\Delta G^{*}$ should be reduced in value.

Finally the viscosity is given by

$$
\eta=\frac{\lambda_{1} \tau}{2 \lambda \mathrm{K} \sinh \frac{V \tau}{2 \mathrm{k} T}}
$$

At the representative value of $\zeta=400$ meters the stress is about $1.3 \times 10^{8}$ dyne $\mathrm{cm}^{-2}$ so that

$$
\eta=3.42 \times 10^{22} \text { poise. }
$$

If on the other hand we assume Newtonian behavior as in future times (22) becomes

$$
\eta=\frac{\lambda_{1} \mathrm{k} T}{V \lambda \mathrm{K}}
$$

and $\eta=4.05 \times 10^{23}$ poises.

It should be mentioned here again that although expressions (14) and (15) are definite functions of the temperature and pressure the assumed value of $T=1,600^{\circ} \mathrm{K}$ used to calculate $V$ and $\Delta G^{*}$ does not enter into the determination of $\eta$. This may be seen by noting that $\eta$ can be expressed solely in terms of $\mathrm{K}_{1}, \mathrm{~K}_{2}, \mathrm{C}_{0}, \mathrm{~A}_{1}$, and the stress. Thus the actual temperature (and pressure) of flow is implicit in these derived constants.

Uncertainties in the values of the presently remaining uplift influence $\eta$ by a factor varying from less than 0.6 to 1.4. Also uncertainties arising from the assumptions embodied in deriving $\mathrm{K}_{1}$ and $\mathrm{K}_{2}$ influence $\eta, V$ and $\mathrm{K}$. It is possible that the multiplicity of uncertainties from these sources could reduce or increase $\eta$ by an order of magnitude. Given these uncertainties $\eta$ falls well within the range of previous values obtained by fluid dynamic methods, and thus provides an independent check on these methods.

Values of the strain rate $\dot{\gamma}$ calculated from the relation (11) fall in the range commonly inferred for a number of geologic processes. For example if $\dot{\zeta}=10 \mathrm{cmyr}^{-1}, \dot{\gamma}=3.17 \times$ $10^{-15} \mathrm{sec}^{-1}$ while the present value is less than 0.1 of this.

The results obtained here are in agreement with previous conclusions that the Fennoscandian uplift data demonstrate non-Newtonian behavior for the Earth's mantle under the stresses and strain rates which prevailed in the past during this uplift. However, as we have seen our analysis indicates that at lower strain rates and stresses which will prevail in future time increasingly Newtonian behavior should occur. Furthermore, the model also corresponds to increasing deviation from Newtonian behavior at high stresses and strain rates which characterized the early period of uplift. From these results we can also conclude that if the kinetic mechanism of flow in the Fennoscandian uplift is the same as that which occurs in other mantle flow processes, stresses of the order of ten bars or less should elicit essentially Newtonian behavior. It is of course possible that the kinetic mechanism would change even under conditions of constant pressure, temperature and strain rate if the composition were altered significantly. Such radical changes could be brought about by higher or lower water content for example.

Those authors who have favored the use of power law formulas for the strain rate have implied discontinuous changes in mechanisms from, for example, vacancy diffusion processes to dislocation climb which have called for corresponding discontinuous changes in $\mathrm{n}$ the power to which the stress is raised. There have been no attempts to analyze processes of mantle flow in terms of several simultaneously acting mechanisms such as was done by HAHN et al. (1967) for the flow of the Yule marble. Although dislocations appear to be common in deformed olivines their presence does not prove that their motion was rate controlling for the deformation as a whole as is implied by KIRBY and RALEIGH (1973). Consequently identification of the mechanisms involved in mantle flow cannot 
at this time be carried beyond the generalized shearing motion utilized in the derivation of equation (5). It seems likely however, that an important role is played by various mechanisms of recrystallization involving complete breakdown and reconstitution of the crystal structure such as occurs in pressure solution of metamorphic minerals for example. A recent review of these processes has been given by ElLiotT (1973).

\section{Viscous Flow on Other Terrestrial Planets}

We may, from the previously discussed evidence of viscous flow on Earth, also expect such phenomena to be operative on other planets which are composed of silicates, oxides, metals, etc. In particular we should expect this to be the case for the terrestrial planets Mercury and Venus, Moon, and Mars since their densities and surface compositions indicate various combinations of these substances. Furthermore we now have sufficient data on the surface details and physical parameters such as temperature to enable us to make at least preliminary evaluations of the extent of viscous behavior on the different terrestrial planets. Rheological properties in fact present us with one of the fertile research opportunities in comparative planetology.

It has recently been revealed that the surface topographies of the smaller terrestrial planets Mercury and Mars are like that of the Moon, characterized by relatively rugged terrain which apparently has resulted from the impact of meteorites and planetessimals (BALDWIN, 1963; MURRY et al., 1974; MCCAUley et al., 1972). By contrast the planet Venus with a diameter and density similar to Earth's apparently has a more subdued terrain (CAMPBELl et al., 1972; GoldSTEIN and RUMSEY, 1975). The reported crater-like structures on Venus (DRISCOLL, 1973) are quite shallow and, as we shall see, probably have a different origin. In terms of surface relief Earth's topography appears to be of intermediate magnitude.

Attention was previously directed to the effect of high lithospheric temperatures on Venus (Mueller, 1963, 1969). If the hot Venusian crustal and subcrustal materials yield by any of the previously discussed viscous flow mechanisms, the viscosity should be highly temperature dependent, since the activation energies are of the order of 100 kilocalories per mole. We may then compare subcrustal layers of similar composition on Venus and Earth by applying the general relation for the temperature dependence of the rate constant:

$$
\frac{\partial \ln \mathrm{K}}{\partial T}=\frac{E^{*}}{\mathrm{R} T^{2}}
$$

By definition the relaxation time $t^{\circ}$ is equal to $1 / \mathrm{K}$. Consequently we can compare the time scale of viscous processes on Venus and Earth by integration of (24) between their respective temperatutes $T_{\mathrm{V}}$ and $T_{\mathrm{E}}$ :

$$
\frac{\mathrm{t}_{\mathrm{V}}^{\circ}}{\mathrm{t}_{\mathrm{E}}^{\circ}}=\exp \frac{E^{*}}{\mathrm{R}}\left(\frac{1}{T_{\mathrm{V}}}-\frac{1}{T_{\mathrm{E}}}\right) .
$$

If for a given lithosperic level where viscous flow occurs $T_{\mathrm{y}}-T_{\mathrm{E}}=100^{\circ} \mathrm{K}$ and if $E^{*}=100 \mathrm{k} \mathrm{cal}$. then $\mathrm{t}_{\mathrm{V}}^{\circ}=10^{-2} \mathrm{t}_{\mathrm{E}}^{\circ}$ so that the time scale for this viscous processes on Venus is contracted two orders of magnitude relative to the same process on Earth. Examination of likely temperature-depth curves for the two planets indicates that actual temperatures in the lower crust and upper mantle of Venus may be as much as $300 \sim$ $400^{\circ} \mathrm{K}$ higher than corresponding levels on Earth (MUELLER, 1969) so that this effect could be much greater than estimated for a temperature difference of $100^{\circ} \mathrm{K}$.

One of the most important consequences of the reduction of viscosity by the high 
temperatures on Venus should be a corresponding reduction of surface relief. Such a reduction of relief could result, for example, from mountain "unbuilding" through viscous gravitational slumping of high relief features, should these come into existence by other processes. It could also come about through the reduction of the dimension of isostatic adjustment and closer approach to true hydrostatic equilibrium. According to the theory of isostasy mountains stand high because they are composed of relatively cool, rigid and light material which forms "roots" extending into denser underlying material. On Venus however, there would be a strong tendency for such roots to disappear by upward and outward flow while the mountain tops would be lowered by slumping. These processes should result in a diminished relief and a more uniform distribution of crustal material than prevails on Earth if other countervailing processes do not exist. An example of this type of analysis may be applied to the reported Venusian "craters" (DRISCOLL, 1973). According to the report radar data indicate that the Venus surface shows shallow circular depressions $21 \sim 100$ miles in diameter which resemble meteoritic impact craters. The shallow nature of these depressions is of course in harmony with the thermally weakened crust as previously discussed and is quite independent of origin. However, an alternative to an impact origin for the craters is suggested by comparison with volcanic processes on Earth and Mars. On the latter planets, the type structure of basic lava is the shield volcano which is built up and persists despite the fact that it is gravitationally unstable. An extreme example is Nix Olympica on Mars (HoRD et al., 1972). On Venus however, the crustal and subcrustal weakness would bring about the rapid collapse of such volcanic edifices and in fact should prevent their formation in the first place. Also the more thoroughly differentiated Venusian lithosphere (MUELLER, 1969) should assure that a low density crust is widespread. Thus the extrusion of basic lavas on the crust should result in the rapid formation of basins around the volcanic centers as shown in Fig. 5. This basining effect would result in surface features similar to terrestrial lopoliths. Furthermore there would also be a tendency for the crust to flow upward and outward beneath the lava flows as is shown in Fig. 5. The general process is similar to that already discussed for post glacial uplift but involves sinking rather than uplift. The equations describing the process of formation of these depressions should also be similar to those presented here with $d$ representing a scale factor for the depression and $\zeta$ representing amount of depression still to be realized at any given time. However, complications would be introduced by the viscous yielding of the crust which does not occur to this extent on Earth. An end result of this crustal flow might be the complete erasure of the depression by return crustal overflow (not shown in Fig. 5) as a result of the basic material sinking out of sight.

The contrast in viscous behavior between Venus and the cooler planets Moon and Mars is particularly great. Recent analyses of Martian topography indicate viscosities at the depth of partial compensation to be of the order of $10^{27}$ poises (PHILLIPS and SAUNDERS, 1975). Similar results are obtained for the Moon (BALDwIN, 1971). It appears that on these bodies only the oldest terrain approaches even regional isostatic compensation. The higher viscosities and expanded relaxation time and distance scales could result from a thermal effect as given by equation (25) or from compositional differences.

It should be stressed that many aspects of these applications of kinetic theory to comparative planetology are highly uncertain. Thus there should be a tendency on Venus for a more thorough basification of subcrustal material than on Earth as a result of the inferred higher degree of differentiation. If the two planets were roughly comparable in bulk composition, the high Venusian temperatures should encourage more rapid and thorough upward movement of the low melting (granitic) fraction than on Earth. This process should result in a strengthening of the subcrust which runs counter to the effect of temperature (MUELLER, 1969). A similar strengthening could result if the Venusian lithosphere is significantly lower in water than that of Earth. Despite these complications however, the observed contrasts in features on the terrestrial planets are in harmony with 
the concept of a strong temperature effect in the viscous responses of their materials.

\section{Applications to Global Tectonics on Earth}

Applications of rheological theory to the hypothesis of postulated global plate motions are obvious and impose important constraints on the type and magnitude of these motions. In broad terms two major types of plate motions have been proposed (LANGSETH et al., 1966; Oxburgh and TurcotTe (1968); Ave'Lallement and Carter, 1970). The most frequently proposed mechanism involves movement of plates by drag of mantle convection currents with the return flow occurring at great mantle depths. In the second mechanism the plates are moved by "push" from the ascending material at the mid-ocean ridges and are "pulled" by gravitational sinking of the down-going slab in the vicinity of the trenches. This pull is thought to result from phase transitions of the slab to denser mineralogy partially as a consequ nce of depressed isotherms within and around the slab (TOKsÖz et al., 1971). In the latter mechanisms substantial differential shear occurs between the plate and the underlying material. However, both models imply extensive shear between the slab and the overlying material.

The proposed geometry of the down-going slab and the superimposition of convection currents on the possible complex layering of the crust and mantle introduce great complexities in rheological behavior. It has been emphasized repeatedly (CooK, 1963; FroIDEVAUX and SCHUBERT, 1975) that the opposing effects of pressure and temperature (equation 7) result in a viscosity minimum at several hundred kilometers within the upper mantle and that this probably coincides with the seismic low velocity zone. Presumably this is also the zone of major horizontal motion associated with post-glacial uplift. In addition the cool down-going slab should have a profound effect on the temperature of the enveloping upper mantle with horizontal temperature gradients exceeding the vertical gradient at certain depths (ToKsöz et al., 1971). Since as we have seen $E^{*}$ appears to be of the order of $100 \mathrm{k} \mathrm{cal} / \mathrm{mole}$, this should result in significant rheological stiffening of mantle material near the slab. Consequently it is to be expected that the slab would accrete mantle material as the major shear zone is displaced some distance from the slab (Fig. 6). This effect should result in retention by the slab of less structural integrity than is usually assumed. For example the type of flexures depicted in the near-slab mantle material by ROBINS and GARDNER (1975) seem unlikely since this material would probably be as viscous as the slab itself.

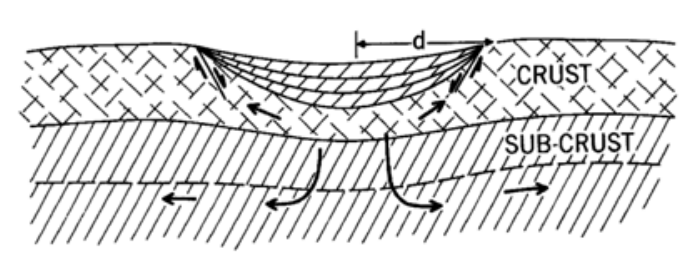

Fig. 5.

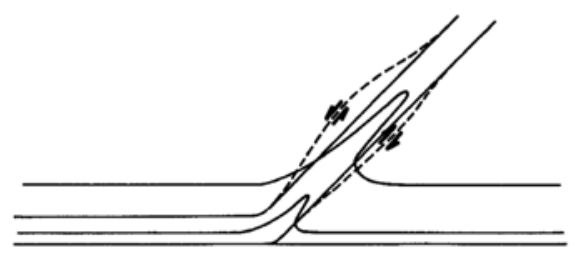

Fig. 6.

Fig. 5. Diagrammatic cross section of the Venus crust and subcrust in the vicinity of a postulated center of basic volcanism. Lava flows and subcrust are shown as hatched and are inferred to be denser than the crust. Direction of viscous flow as shown by full arrows. Shear along faults is shown by half arrows. Fig. 6. Diagrammatic cross section of down-going slab of oceanic crust as postulated in plate tectonic theory. Straight full lines represent slab boundaries at $45^{\circ}$ inclination. Dashed lines with half arrows indicate regions of maximum shearing motion between accreted mantle material on slab and surrounding mantle. Curved lines represent isotherms. 
Finally there is a more general and widespread rheological consequence that follows from the models which have been discussed here. This is an expected stiffening or increase in viscosity of the mantle with time. Such stiffening would result from virtually all known planetary differentiation processes leading to a more stable form. Example are dehydration, basification, cooling as a result of heat conduction and convection, and the upward transfer of radioactive materials with time. The same tendencies are to be expected on the terrestrial planets and indeed have been postulated for Mars (PHILLIPS and SAUNDERS, 1975). The consequences of this process to global tectonics should be significant and need to be explored more fully.

\section{ACKNOWLEDGEMENT}

I thank BARBARA LOWERY for doing the curve fitting and for other assistance as well as for fruitfull discussions of the subject matter.

\section{REFERENCES}

AITYUShKov, E. V. (1967) On the isostatic equilibrium of the Earth's crust, Geophys. J. 14, 251260.

AVE'Lallemant, H. G. and CarTer, N. L. (1970) Syntectonic recrystallization of olivine and modes of flow in the upper mantle, Geol. Soc. Am. Bull. 81, 2203-2220.

Baldwin, R. B. (1963) The measure of the moon, Univ. Chicago Press, Chicago.

BALDwIN, R. B. (1971) The question of isostacy on the Moon. Phys. Earth Planet. Interiors. 4, 167179.

Campbell, D. B., Ingalls, R. P., Pettengill, G. H., and Shapiro, I. I. (1972) Venus: Topography revealed by radar data. Science $175,514-516$.

CARTER, N. L. and Ave'Lallemant, H. G. (1970) High temperature flow of dunite and periodite. Geol. Soc. Am. Bull. 81, 2181-2202.

Clark, S. P., JR., and RINGWOOD, A. E. (1964) Density distribution and constitution of the mantle. Rev. Geophys. 2, 35-88.

COBEL, R. L. (1963) A model for boundary diffusion controlled creep in polycrystalline materials. J. Appl. Phys. 34, 1679-1682.

CooK, M. A. (1963) Viscosity-depth profiles according to the Ree-Eyring viscosity relations. J. Geophys. Res. 68, 3515-3520.

DRISCOLL, E. (1973) Our cratered sister planet. Science News 104, 72-73.

ElliotT, D. (1973) Diffusion flow laws in metamorphic rocks. Geol. Soc. Am. Bull. 84, 2645-2664.

FroideVAuX, C. and SCHUberT, G. (1975) Plate motion and structure of the continental asthenosphere. A realistic model of the upper mantle. J. Geophys. Res. 80, 2553-2564.

GlassTONE, S. LAIDLER, K. J. and EYRING, H. (1941) The theory of rate processes, McGraw-Hill, New York.

GoldSTEIN, R. M. and RUMSEY, H. C. (1975) Venus - characteristics and history. Trans. Am. Geophys. Union. 56, 388 (Abst.).

HAHN, S. J., REE, T. and EYRING, H. (1967) Mechanism for the plastic deformation of Yule marble. Geol. Soc. Am. Bull. 78, 773-782.

HaSkell, N. A. (1937) The viscosity of the astenosphere. Am. J. Sci. 33, 22-28.

HEARD, H. C. and RAlEigh, C. B. (1972) Steady state flow in marble at $500^{\circ}$ to $800^{\circ} \mathrm{C}$. Geol. Soc. Am. Bull. 83, 935-956.

HERRING, C. (1950) Diffusional viscosity of a polycrystalline solid. J. Appl. Phys. 21, 437-445.

HORD, C. W., BARTH, C. A., and STEWART, A. I. (1972) Mariner 9 ultraviolet spectrometer experiment: Photometry and topography of Mars. Icarus 17, 443-456.

KIRBY, S. H., and R ALEIGH, C. B. (1973) Mechanisms of high-temperature solid state flow in minerals and ceramics and their bearing on the creep behavior of the mantle. Geophys. 19, 165-194.

LANGSETH, M. G., LEPINCHON, X., and EWING, M. (1966) Crustal structure of the mid-oceanic ridges, 
5. Heat flow through the Atlantic Ocean floor and convection currents. J. Geophys. Res. 71, 5321-5355.

LIDÉN, R. (1938) Der Senkvartära strandförskjutningens förlopp och Kronologi. Ångermanland. Geol. Foren. Forhandl. 60, 397-404.

LliboutRY, L. A. (1971) Rheological properties of the astenosphere from Fennoscandia data. $J$. Geophys. Res. 76, 1433-1445.

McCauley, J. F., Carr, M. H. CutTs, J. A., Hartman, W. K. Masursky, H., Milton, D. J., Sharp, R. P. and WILHELMS, D. E. (1972) Preliminary Mariner 9 report on the geology of Mars. Icarus $17,289-327$.

MCCONNELL, R. K., JR. (1968) Viscosity of the mantle from relaxation time spectra of isostatic adjustment, J. Geophys. Res. 73, 7089-7105.

MCKenZIE, D. P. (1967) The viscosity of the mantle. Geophys. J. 14, 297-305.

MUELleR, R. F. (1963) Chemistry and petrology of Venus, preliminary deductions. Science 141, 1046-1047.

MUELLER, R. F. (1969) Effect of temperature on the strength and composition of the lithosphere of Venus. Nature 224, 354-356.

MurRy, B. C., Belton, M. J. S., Danielson, G. E., Davis, M. E., Gault, D., HaPKe, B., O'Leary, B., STROM, R. G., SUOMI, V., and TRASK, N. (1974) Mariner 10 pictures of Mercury: First results. Science 184, 459-461.

NABARRO, F. R. N. (1948) Deformation of crystals by the motion of single ions, Report of a conference on the strength of solids, Phys. Soc. (London) Proc. $75 \mathrm{p}$.

NisKanen, E. (1948) On the viscosity of the Earth's interior and crust. Ann. Acad. Sci. Fenn. Ser. A III, 15, 22.

OXBURGH, E. R. and TURCOTTE, D. L. (1968) Mid-ocean ridges and geotherm distribution during mantle convection. J. Geophys. Res. 73, 2643-2661.

PoSt, R. H., JR. and GriggS, D. T. (1973) The Earth's mantle: Evidence of non-Newtonian flow. Science 181, 1242-1244.

Raleigh, C. B. (1968) Mechanisms of plastic deformation in olivine. J. Geophys. Res. 73, 5391.

REE, T. and EYRING, H. (1955) Theory of non-Newtonian flow. I. solid plastic system. J. Appl. Phys. 26, 793-800.

RoBINS, B. and GaRdNER, P. M. (1975) The magmatic evolution of the Seiland province, and Caledonian plate boundaries in northern Norway. Earth and Planet. Sci. Lett. 26, 167-178.

Sauramo, M. (1958) Die Geschichte der Ostsee. Ann. Acad. Sci. Fennicae A(3), 44.

SherbY, O. and Simmad, M. T. (1961) Prediction of atomic mobility in metallic systems. Trans. Am. Soc. Metals 54, 227-240.

Shewman, P. G. (1963) Diffusion in solids, McGraw-Hill, New York.

TAKEUCHI, H. and HASEgaWA, Y. (1965) Viscosity distribution within the Earth. Geophys. J. 9, 503-508.

TOKSÖZ, M. N. MINER, J. W. and JULIAN, B. R. (1971) Temperature field and geophysical effects of down-going slab. J. Geophys. Res. 76, 1113-1138.

VON BEMmELEN, R. W., and BERLAGE, H. P. (1954) Versuch einer mathematischen Behandlung geotektonischer Bewegung unter besonderer Berücksichtigung der Undations Theorie. Gelands. Beitr. Z. Geophys. 43, 19-55.

VENING-MEINESZ, F. A. (1937) The determination of the Earth's plasticity from the post-glacial uplift of Scandinavia. Poc. Kon. Akad. Wet. Amsterdam 40, 653-662.

WALCOTT, R. F. (1973) Structure of the Earth from glacio-isostatic rebound. Ann. Rev. Earth and Planet. Sci. 1, 15-37.

Weertman, J. (1968) Dislocation climb theory of steady state creep. Trans. Am. Soc. Metal. 61, 681-694.

Weertman, J. (1970) The creep strength of the Earth's mantle. Rev. Geophys. 8, 145-168. 